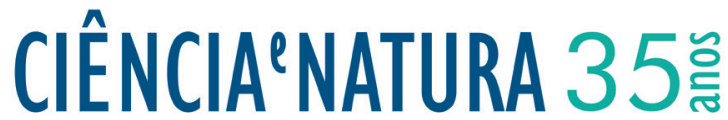

\section{Análise da Evapotranspiração sobre o Seridó Nordestino em cenários de aquecimento}

\author{
Analysis of Evapotranspiration over the Northeast Seridó in heating scenarios \\ Edmir dos Santos Jesus ${ }^{1}$,Arthur Mattos ${ }^{2}$, Nilzele Vilhena Gomes Jesus ${ }^{3}$ \\ ${ }^{1}$ Departamento de Física Teórica e Experimental, Universidade Federal do Rio Grande do Norte,RN,Brasil \\ ${ }^{2}$ Laboratório de Recursos Hídricos e Saneamento Ambiental, Universidade Federal do Rio Grande do \\ Norte,RN,Brasil \\ ${ }^{3}$ Programa de Pós-Graduação em Meteorologia, Universidade Federal do Rio Grande do Norte,RN,Brasil
}

\begin{abstract}
Resumo
O conhecimento da transferência de água de uma superficie natural é de suma importância nos diferentes campos do meio científico, especialmente nas aplicações da Meteorologia e da Hidrologia. A transferência de água de uma superficie qualquer para a atmosfera, por meio dos processos de evaporação e transpiração, é denominada evapotranspiração, ou seja, transferência conjunta de água do solo pela evaporação e da planta pela transpiração. Nesse contexto o objetivo dessa pesquisa foi analisar as anomalias de evapotranspiração sobre a microrregião do Seridó no Rio Grande do Norte, a partir da climatologia, utilizando do método de evapotranspiração de referência proposto por Hargreaves-Samani, conforme os cenários descritos pelo IPCC de aumento na temperatura do ar em periodos chuvoso, de transição e seco. Esses resultados nos mostraram que com relação aos cenários futuros, verifica-se que houve grande diferença no aumento da evapotranspiração anual e mensal para o cenário entre 2090-2099. Valores esses que superam a própria classificação climática de Thornthwaite.
\end{abstract}

Palavras-chave: temperatura; semiárido; precipitação; hargreaves-samani

\begin{abstract}
Knowledge of the transfer of water from a natural surface is of paramount importance in various fields of scientific, especially in the Meteorology and Hydrology applications. The transfer water of any surface to the atmosphere through the processes of evaporation and transpiration is called evapotranspiration, in other words transfer of water from the soil by evaporation and plant transpiration. In this context, the objective of this research was to analyze the anomalies of evapotranspiration on the micro Serido in Rio Grande of the North, from the climatology, using the method of reference evapotranspiration proposed by Hargreaves-Samani, as described by the IPCC scenarios of increased air temperature during wet, transition and dry periods. These results showed that with respect to future scenarios, it appears that there was a great difference in the increase in annual and monthly evapotranspiration for scenario between 2090-2099. Values that exceed the actual climatic classification of Thornthwaite.
\end{abstract}

Keywords: temperature; semiarid; precipitation; hargreaves-samani 


\section{Introdução}

Dada à importância do conhecimento das exigências hídricas das culturas, tendo sua aplicação direta na agricultura irrigada e não irrigada, é essencial que o uso racional dos recursos hídricos possibilite o dimensionamento adequado dos sistemas de irrigação, bem como um manejo adequado de água.

O conhecimento da transferência de água de uma superfície natural é de suma importância nos diferentes campos do conhecimento científico, especialmente nas aplicações da Meteorologia e da Hidrologia. A evapotranspiração se dá pela transferência de água na forma líquida para vapor, através da água do solo pela evaporação e da planta pela transpiração. Este termo foi utilizado por Thornthwaite em substituição ao usado antes da década de 40, que era de uso consuntivo, o qual considerava apenas a água retida na planta (PEREIRA et al., 2002). Normalmente se estima a evapotranspiração, devido à dificuldade de se separar os processos de evaporação (transferência de água diretamente das superfícies para a atmosfera) e transpiração (transferência de água dos organismos vegetais e animais para a atmosfera) (MOTA, 1977).

A temperatura do ar tem sua importância pelo fato de ser um dos elementos mais disponíveis em estações meteorológicas. Na ausência de dados de radiação, esse elemento meteorológico pode ser usado como indicativo de energia no sistema estudado. A radiação absorvida pela atmosfera aumenta a temperatura do ar, contribuindo para o aumento do processo de evapotranspiração. Dessa forma a temperatura do ar interfere nas condições ambientais, interagindo com outras variáveis de importância para o processo de evapotranspiração. Portanto, é de fundamental importância as medições da temperatura do ar, em qualquer instante, principalmente naqueles horários recomendados pela Organização Meteorológica Mundial (OMM), incluindo neste caso as temperaturas máximas e mínimas do ar ocorridas em um período de 24 horas, e na impossibilidade destas últimas medidas, deve-se recorrer a métodos de estimativas (AZEVEDO, 1999).

Os autores Silva et al,.(2005) verificaram que o método de Hargreaves-Samani apresentou resultados satisfatórios quando comparados ao método padrão de Penman-Monteith (Fao 56) (Allen et al. 1998), sendo possível indicá-lo para ser usado em Petrolina-PE. Assim como, Santos, W. O. et al., (2010) para a região de Mossoró-RN; Silva et al., (2011) que estimaram e verificaram o bom desempenho desse método em Uberlândia-MG; Fanaya Júnior et al., (2012) em Aquidauana-MS e Back (2008) em Urussanga-SC.

Com relação a avaliação de cenários, Santos, D. N. D. et al., (2010) avaliaram as condições climáticas atuais do Nordeste Brasileiro e elaboraram cenários climáticos para os anos de 2050 e 2100, utilizaram das séries temporais de temperatura média do ar e precipitação pluvial, correspondentes ao período de 1961 a 2007 de 89 localidades da região e verificaram tendências crescentes nas séries temporais de temperatura do ar, significativas estatisticamente pelo teste de Mann-Kendall, tanto para o período estudado como para os cenários de 2050 e 2100.

Mattos et al., (2013) que avaliaram as componentes do balanço hídrico climatológico mensal através do método de Thornthwaite e Mather em seis diferentes cenários, conforme o relatório do IPCC, na localidade de Cruzeta, viram que a deficiência hídrica foi mais pronunciada em todos os cenários de simulação. Os resultados mostraram que não ocorreu período de excedência hídrica, além de que os componentes do balanço hídrico foram influenciados diretamente pela precipitação, limitando diretamente a disponibilidade e o armazenamento de água, e consequentemente retardando o processo de evapotranspiração.

O objetivo dessa pesquisa foi analisar as anomalias de evapotranspiração sobre a microrregião do Seridó, a partir da climatologia, utilizando do método proposto por Hargreaves-Samani, conforme os cenários apresentados descritos pelo IPCC de aumento na temperatura do ar em períodos chuvoso, de transição e seco.

\section{Material e métodos}

Para a realização deste trabalho foram selecionados os dados meteorológicos mensais dos municípios pertencentes a região de estudo como a temperatura do ar $\left({ }^{\circ} \mathrm{C}\right)$ que foram estimados para cada município da microrregião (a partir das coordenadas geográficas) por meio do software Estima_T (Cavalcanti et al., 2006), do Departamento de Ciências Atmosféricas (DCA), da Universidade Federal de Campina Grande (UFCG). Estes dados estimados levam em consideração a série temporal de 30 anos (1961 a 1990) através das estações meteorológicas convencionais instaladas no Rio Grande do Norte pelo Instituto Nacional de Meteorologia (INMET). Além dos dados de radiação solar (MJ.m ${ }^{-2}$.dia $\left.{ }^{-1}\right)$ que foram obtidas empiricamente por planilha eletrônica ERS.V.1.3_2002 desenvolvida por D'Angiolella (2003).

A partir destes dados foram confeccionados mapas de evapotranspiração estimada pelo método proposto dos meses de março, julho e outubro. Estes foram feitos através do traçado de isolinhas, obtidos utilizando o método de krigagem de interpolação espacial no software SURFER versão 8.0.

A série de dados foi obtida de Estações Meteorológicas de Superfície monitoradas pelo $3^{\text {o }}$ DISME (Distrito de Meteorologia), pela Empresa de Pesquisa Agropecuária do Rio Grande do Norte (EMPARN), os quais correspondem ao período de 1963 a 2008; além dos dados das Estações Meteorológicas Automáticas (EMA) do Instituto Nacional de Pesquisas Espaciais (INPE) e as Semi-automáticas (EMSA) monitoradas pelo Laboratório de Recursos Hídricos e Saneamento Ambiental 
(LARHISA) da Universidade Federal do Rio Grande do Norte (UFRN) através do Projeto MEVEMUC (UFRN/ FINEP) no ano de 2012.

O método utilizado para as estimativas de evapotranspiração de referência foi de Hargreaves-Samani (1985), cujo método tem sido indicado ao uso na região semiárida, pois requer apenas de dados de temperatura do ar segundo a equação proposta pelo autor:

$$
\text { EToHS }=23 \cdot 10^{-4} \cdot \frac{R_{o}}{\lambda}\left(T_{\text {med }}+17,8\right) \sqrt{\left(T_{\text {máx }}-T_{\text {min }}\right)}
$$

Em que: $T_{\text {med }}, T_{\text {máx }}$ e $T_{\text {min }}$ representam, as temperaturas $\left({ }^{\circ} \mathrm{C}\right)$ média, máxima e mínima do ar, respectivamente; $R_{o}$ é a radiação solar no topo da atmosfera, expressa em MJ.m ${ }^{-2} \cdot$ dia $^{-1}$ e $\lambda$ é o calor latente de evaporação $\left(2,45 \mathrm{MJ} \cdot \mathrm{Kg}^{-1}\right)$.

De acordo com as projeções do Painel Internacional de Mudanças Climáticas - IPCC (Intergovenmental Panel Climate Change) (4⿳⺈⿴囗十一 Relatório de Avaliação - 2007), seis cenários de aquecimento do ar e da superfície do globo foram propostos para prováveis possibilidades de ocorrência, no século 21, de dias mais quentes, temporadas quentes e ondas de calor, forte regime de precipitação, aumento das estiagens e da intensidade da atividade de ciclones tropicais e elevação do nível do mar.

As melhores estimativas e as prováveis faixas com relação ao aquecimento médio do ar e das superfícies do globo para os seis cenários de emissão, os quais são apresentados na Tabela 1, sendo os aquecimentos médios da superfície do globo projetados para o final do século 21 (anos de 2090-2099) relacionado ao período de 1980-1999.
TABELA 1. Cenários segundo o IPCC e suas respectivas variações de temperatura do ar quanto à média global.

$$
\text { Mudanças na temperatura do ar }
$$

Cenários (em 2090-2099 relativo a 1980-1999)

$$
\text { Melhor estimativa }\left({ }^{\circ} \mathrm{C}\right) \text { Faixa provável }\left({ }^{\circ} \mathrm{C}\right)
$$

\begin{tabular}{lll}
\hline B1 & 1,8 & 1,1 a 2,9 \\
A1T & 2,4 & 1,4 a 3,8 \\
B2 & 2,4 & 1,4 a 3,8 \\
A1B & 2,8 & 1,7 a 4,4 \\
A2 & 3,4 & 2,0 a 5,4 \\
A1FI & 4,0 & 2,4 a 6,4 \\
\hline
\end{tabular}

FONTE: Adaptado de Solomon et al.,(2007).

\subsection{Aréa de estudo}

A região de estudo corresponde à microrregião do Seridó, situada entre as latitudes de $6^{\circ} 06^{\prime}$ e $7^{\circ} 00^{\prime}$ Sul e longitudes de $37^{\circ} 25^{\prime}$ e $36^{\circ} 15^{\prime}$ Oeste (Figura 1). Subdividida em seridó oriental e ocidental, a região representa uma das dez do Estado do Rio Grande do Norte que abrange 17 municípios, e que ocupa uma área territorial de $9.372 \mathrm{~km}^{2}$ correspondendo a quase $18 \%$ do Estado (IBGE, 2010). A microrregião se encontra inserida na região semiárida do Nordeste Brasileiro com regime

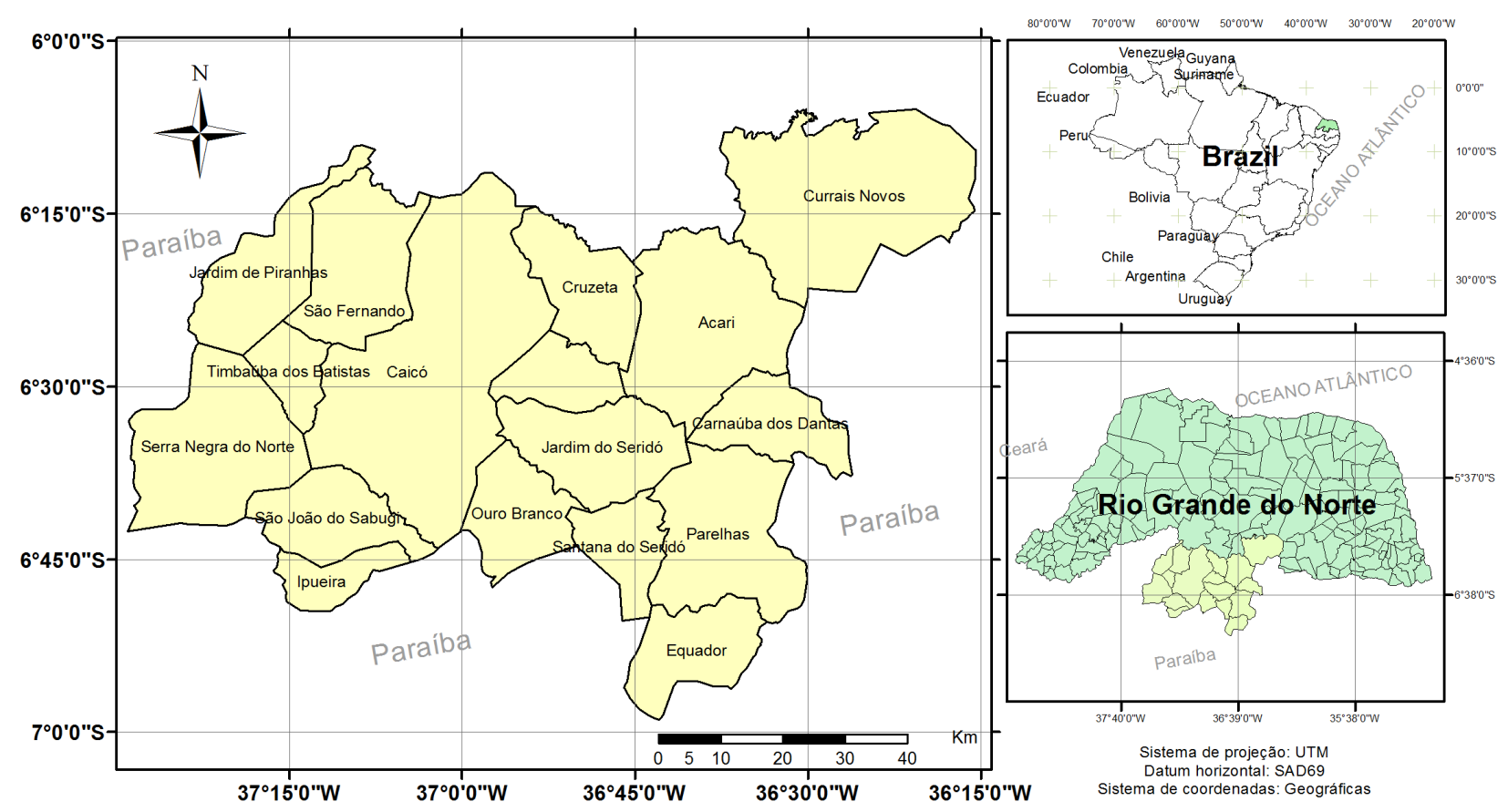

Figura 1. Localização geográfica dos municípios na microrregião do Seridó.

Fonte: Base de dados do IBGE (2010). 
pluviométrico bastante irregular tanto espacialmente quanto temporalmente. Segundo a classificação climática de Thornthwaite (1948), o clima desta região é DdA'a', ou seja, semiárido, megatérmico, com excedente hídrico pequeno ou nulo e concentração da evapotranspiração nos meses de verão igual a 26\%, e atingindo uma média anual de $1.464 \mathrm{~mm}$.

Segundo Isaias et al., (1992) a área semiárida possui uma vegetação predominante da caatinga, cuja feição mais típica é representada, conforme por um estrato rasteiro composto principalmente por gramíneas, acima do qual emergem arbustos e árvores de baixo ou médio porte. A atividade econômica principal do Seridó é a agropecuária. Entretanto, a falta de água no solo torna-se a principal limitação para o pequeno agricultor, não apenas pelo seu volume total anual de precipitação pluvial, mas pela distribuição irregular. Fato reforça a necessidade de um monitoramento ambiental contínuo na microrregião do Seridó.

Sob o ponto de vista climático o Nordeste Brasileiro (NEB) apresenta uma alta variedade, podendo-se verificar desde o clima semiárido no interior da Região, com precipitação acumulada inferior a $500 \mathrm{~mm}$ por ano, até o clima chuvoso, observado principalmente na costa leste da região, com precipitação acumulada anual superior a $1500 \mathrm{~mm}$ (KOUSKY e CHU, 1978).

Segundo RAO et al., (1993) ao norte do NEB a estação chuvosa principal é de março a maio, no sul e sudeste as chuvas ocorrem principalmente durante o período de dezembro a fevereiro e no leste a estação chuvosa concentra-se no período de maio a julho. A principal estação chuvosa do NEB, que inclui o norte e o leste da região, é de abril a julho e explica $60 \%$ da chuva anual e a estação seca, na maior parte da região, ocorre de setembro a dezembro. Os meses de novembro, dezembro e janeiro representam meses chuvosos para os setores sul e sudoeste do NEB, devido atuação de sistemas transientes, como Zona de Convergência do Atlântico Sul (ZCAS) e Sistemas Frontais (SFs) que influenciam o regime de precipitação nestes setores durante este período do ano. Já sobre a microrregião os meses de agosto, setembro, outubro e novembro representam pouco abaixo dos $10 \mathrm{~mm}$ mensais, o que confirma como sendo meses de pouca precipitação.

\section{Resultados}

A seguir os resultados mostram os comparativos entre a climatologia da precipitação, a evapotranspiração e os valores estimados de EtoHS para 3 meses representativos do ano.

A Figura 2 mostra a normal climatológica da precipitação que varia ao longo do ano de 600 a $800 \mathrm{~mm}$ sobre a microrregião do Seridó, a partir de dados da EMPARN (1963-2008). Os meses que mais se destacam como chuvosos são os de fevereiro, março e abril com valores pouco acima de $100 \mathrm{~mm}$ na porção central na direção leste-oeste do Seridó. Estes acumulados são principalmente devido à atuação do sistema conhecido como a Zona de Convergência Intertropical (ZCIT) que atua sobre esta faixa da microrregião durante este período do ano.

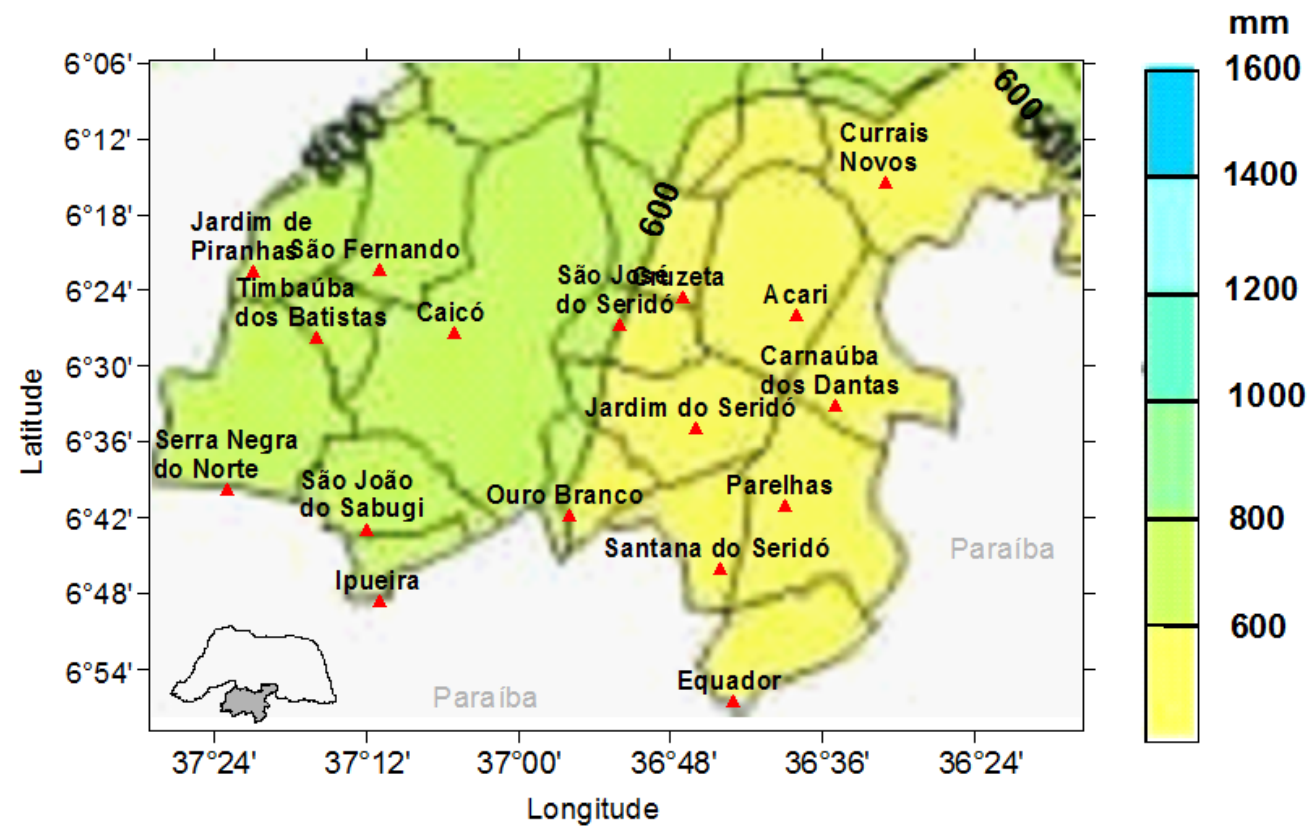

Figura 2. Distribuição espacial da Precipitação anual sobre a microrregião do Seridó. Fonte: EMPARN (2010) 


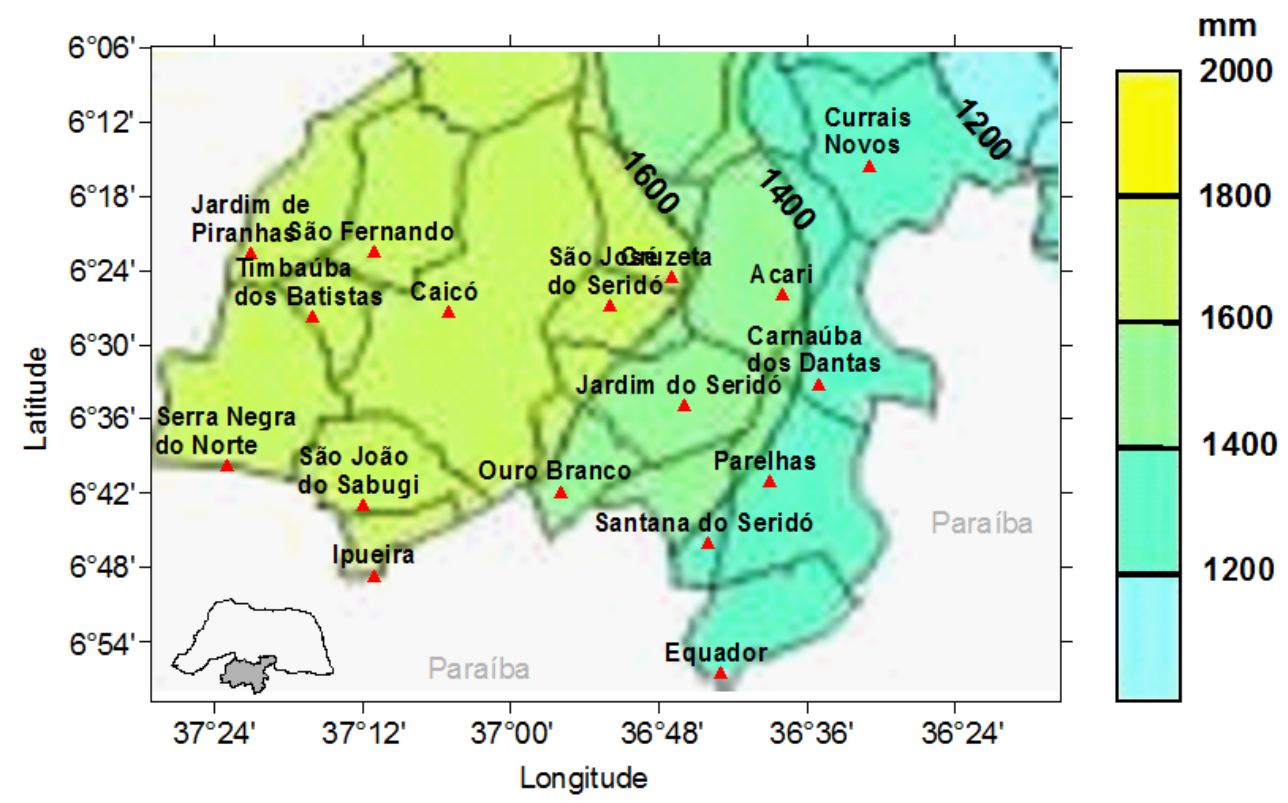

Figura 3. Distribuição espacial da evapotranspiração sobre a microrregião do Seridó. Fonte: EMPARN (2010)

A Figura 3 mostra a climatologia da distribuição anual da evapotranspiração sobre a microrregião do Seridó, onde se observa valores crescentes na direção oeste, entre $1.200 \mathrm{~mm}$ (em Currais Novos) à pouco mais que $1.600 \mathrm{~mm}$ (como em Cruzeta, São José do Seridó, Caicó, São João do Sabugi, Jardim de Piranhas e Serra Negra do Norte).

A Figura 4 mostra a distribuição anual da evapotranspiração conforme as estimativas obtidas pelo método de EtoHS, onde observa-se valores entre $1.700 \mathrm{~mm}$ (em Currais Novos) à $2.000 \mathrm{~mm}$ (Jardim de Piranhas e Serra Negra do Norte). Comparado a normal climatológica
(Figura 3) verifica-se que a estimativa de evapotranspiração espacializa os valores na mesma direção de aumento de leste à oeste do Seridó. Valores este que justificam a grande transferência d'água para a atmosfera anualmente. A região central do Seridó registra em torno de $1.800 \mathrm{~mm}$ de evapotranspiração anual.

A seguir, a Figura 5 mostra a distribuição espacial das anomalias de evapotranspiração obtidas a partir dos dados estimados em relação ao total anual conforme os cenários descritos. Os aumentos se referem aos acréscimos na temperatura média global (Tabela 1), cujo aumento de $0,5^{\circ} \mathrm{C}$ refere-se a um cenário bem pouco provável;

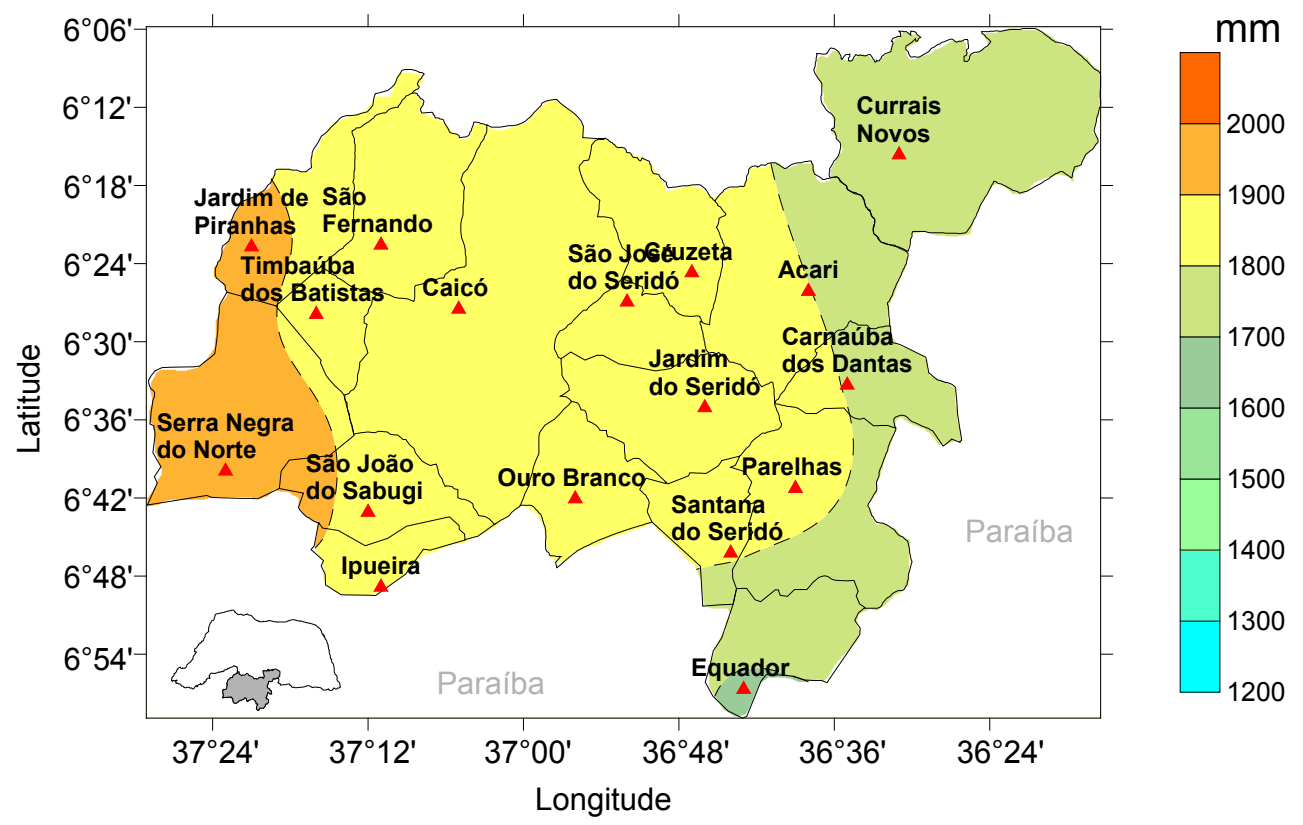

Figura 4. Distribuição espacial da evapotranspiração anual estimada pelo método de Hargreaves-Samani sobre a microrregião do Seridó. 

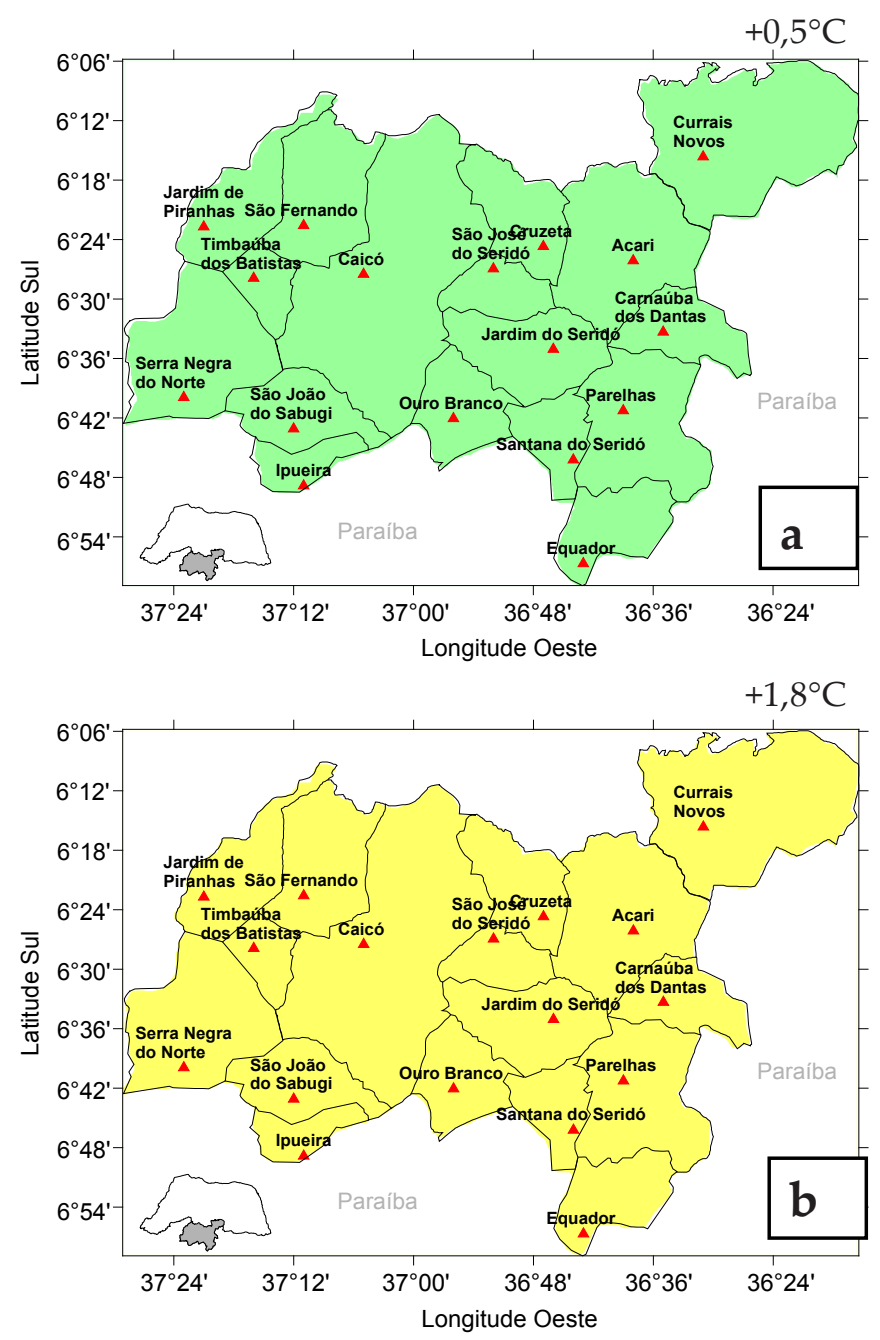

$+4,0^{\circ} \mathrm{C}$
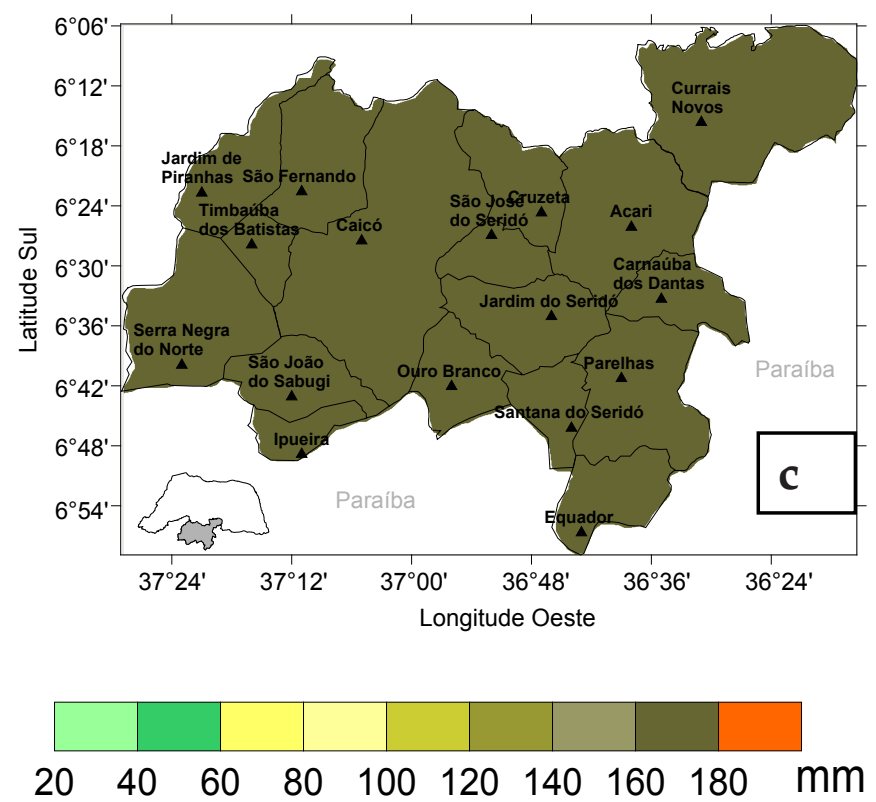

Figura 5. Distribuição espacial de anomalia da EtoHS anual segundo os cenários (alta de $0,5^{\circ} \mathrm{C}$ ) (a), B1 (alta de $1,8^{\circ} \mathrm{C}$ ) (b) e A1FI (alta de $4,0^{\circ} \mathrm{C}$ ) (c). o cenário a $1,8^{\circ} \mathrm{C}$ refere-se a um otimista e a $4,0^{\circ} \mathrm{C}$ ao cenário pessimista.

Nota-se que com o aumento previsto na temperatura do ar de $0,5^{\circ} \mathrm{C}$ (Figura 5a), a anomalia de evapotranspiração varia em torno de $20 \mathrm{~mm}$ a mais no total anual. Ainda assim, esse valor fica abaixo dos valores previstos pelos outros cenários, como de 60 a $80 \mathrm{~mm}$ (B1) (Figura 5b) e acima dos $160 \mathrm{~mm}$ (A1FI) (Figura 5c) em toda a microrregião.

Na descrição desses cenários verifica-se que um pequeno aumento na temperatura média do ar implicaria nos valores finais de evapotranspiração estimados pelo método de EtoHS. Durante o ano, o período chuvoso se instala no trimestre (Fev-Mar-Abr), enquanto que o período de transição se estende no trimestre (Mai-Jun-Jul), e os meses subsequentes, setembro, outubro, novembro e dezembro, como os mais secos. Essa variação nos valores de evapotranspiração dá-se conforme a distribuição da precipitação (Figura 2) o que implicaria em déficit hídrico sobre o Seridó durante o ano.

A Figura 6 mostra as comparações entre os meses de março, julho e outubro segundo sua climatologia e estimativa da evapotranspiração obtida pelo método de HS.

O mês de março (Figura 6a) considerado como sendo o mais chuvoso durante o período, mostra que climatologicamente a evapotranspiração apresenta valores abaixo dos $150 \mathrm{~mm}$ em toda a microrregião. Comparado aos valores estimados pelo método de HS vê-se que são compatíveis, conforme a Figura $6 b$.

A Figura 6c, mostra o mês de julho como sendo um mês de transição, e como se pode ver a evapotranspiração aumenta na metade oeste do Seridó de 100 a $150 \mathrm{~mm}$ em média, o que comparado aos valores estimados do mês (Figura 6d) ficando acima de $100 \mathrm{~mm}$ em toda a região.

O mês de outubro (Figura 6e), considerado como o mês mais crítico, por ser o mais seco do ano e com isso representar maior taxa de transferência de água para a atmosfera (metade oeste do Seridó acima de $150 \mathrm{~mm}$ ), vê-se que os municípios à Oeste configuram como sendo os que registram os maiores valores de evapotranspiração comparados aos da região leste. Isso ocorre devido aos fatores como a intensa disponibilidade de radiação solar, pouca nebulosidade, baixa na umidade do ar e a alta temperatura que ocasionam à alta taxa de evapotranspiração contribuindo para a forte convecção e consequentemente a intensidade dos ventos sobre a microrregião. Localidades como Timbaúba dos Batistas, Serra Negra do Norte, São Fernando, Jardim de Piranhas, Ipueira e Caicó chegaram a registrar valores em torno de $200 \mathrm{~mm}$ durante esse período, confirmando com os valores estimados (Figura 6f).

A Figura 7 mostra as anomalias referentes aos cenários propostos para o mês de março conforme o aumento na temperatura média do ar de $0,5^{\circ} \mathrm{C}, 1,8^{\circ} \mathrm{C}$ e $4,0^{\circ} \mathrm{C}$.

O mês de março apresenta as anomalias com os valores mínimos para um cenário pouco provável $\left(a ̀ n, 5^{\circ} \mathrm{C}\right)$ que ficaram entre 2 e 3 mm.mês ${ }^{-1}$ (Figura 7a); para o cenário 


\section{Climatologia de Eto}
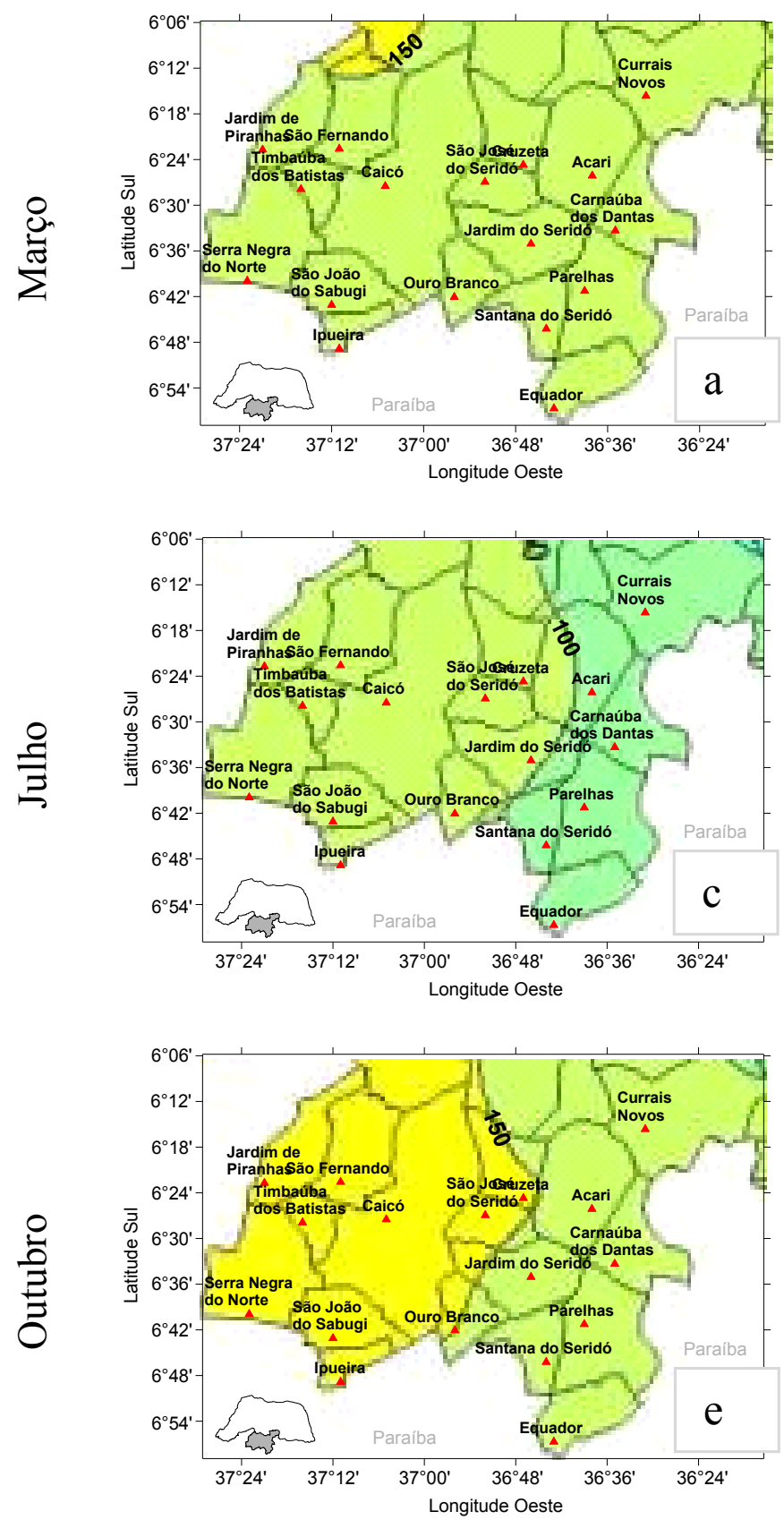

\section{Eto por Hargreaves-Samani}
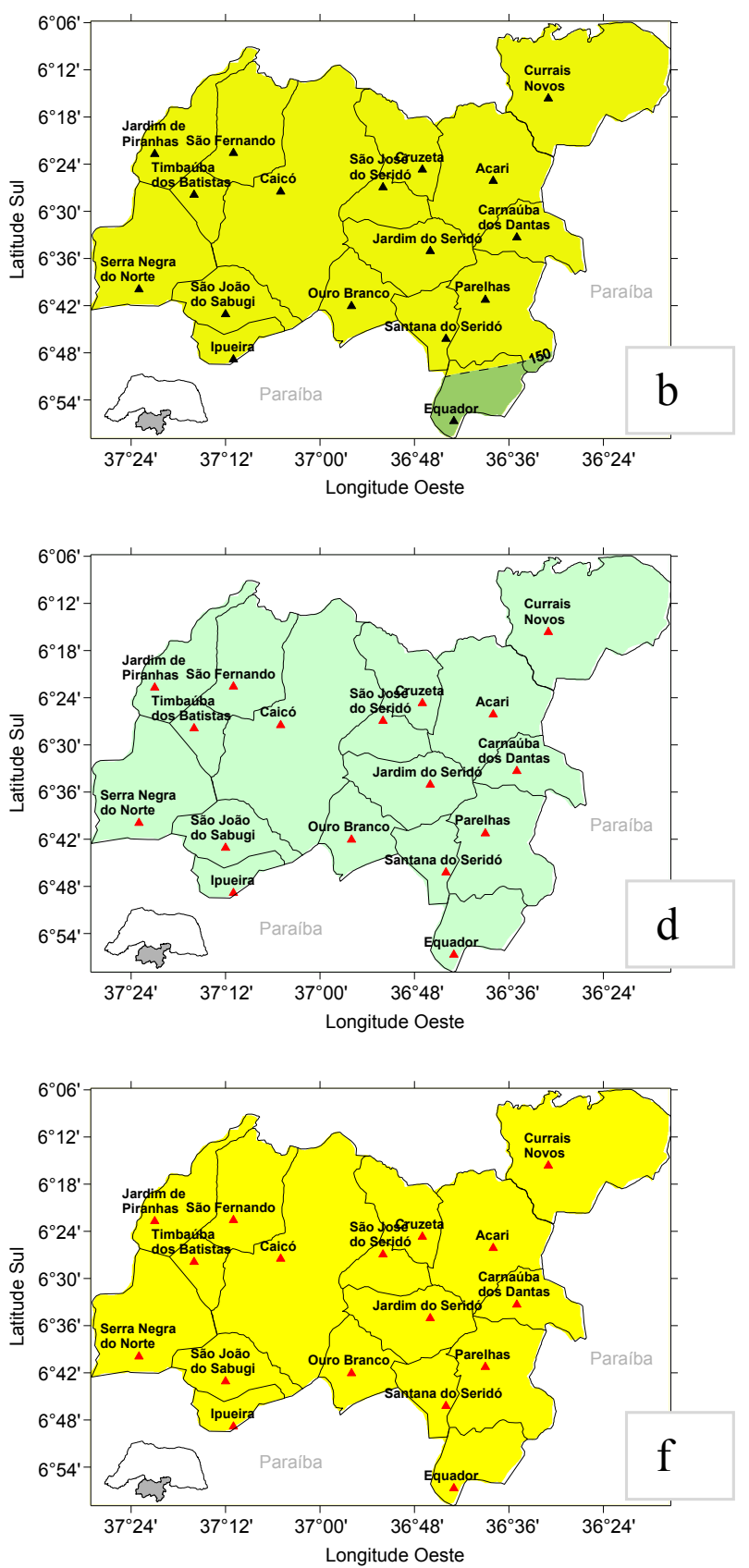

Figura 6. Distribuição espacial da climatologia de evapotranspiração para os meses de Março (a), Julho (c) e Outubro (e) com seu respectivo mês estimado pelo método de Hargreaves-Samani para Março (b), Julho (d) e Outubro (f).

B1 a diferença gradual fica por entre 6 e $8 \mathrm{~mm} \cdot \mathrm{mês}^{-1} \mathrm{em}$ toda a região (Figura $7 b$ ). E para um cenário pessimista em que essa diferença tende a ser superior aos $14 \mathrm{~mm}$ para esse mês, em torno de $9 \%$ (Figura 7c).
Esses valores só confirmam o que poderá haver com os aumentos previstos na temperatura média do ar, de posse das estimativas de Hargreaves-Samani. 
$+0,5^{\circ} \mathrm{C}$
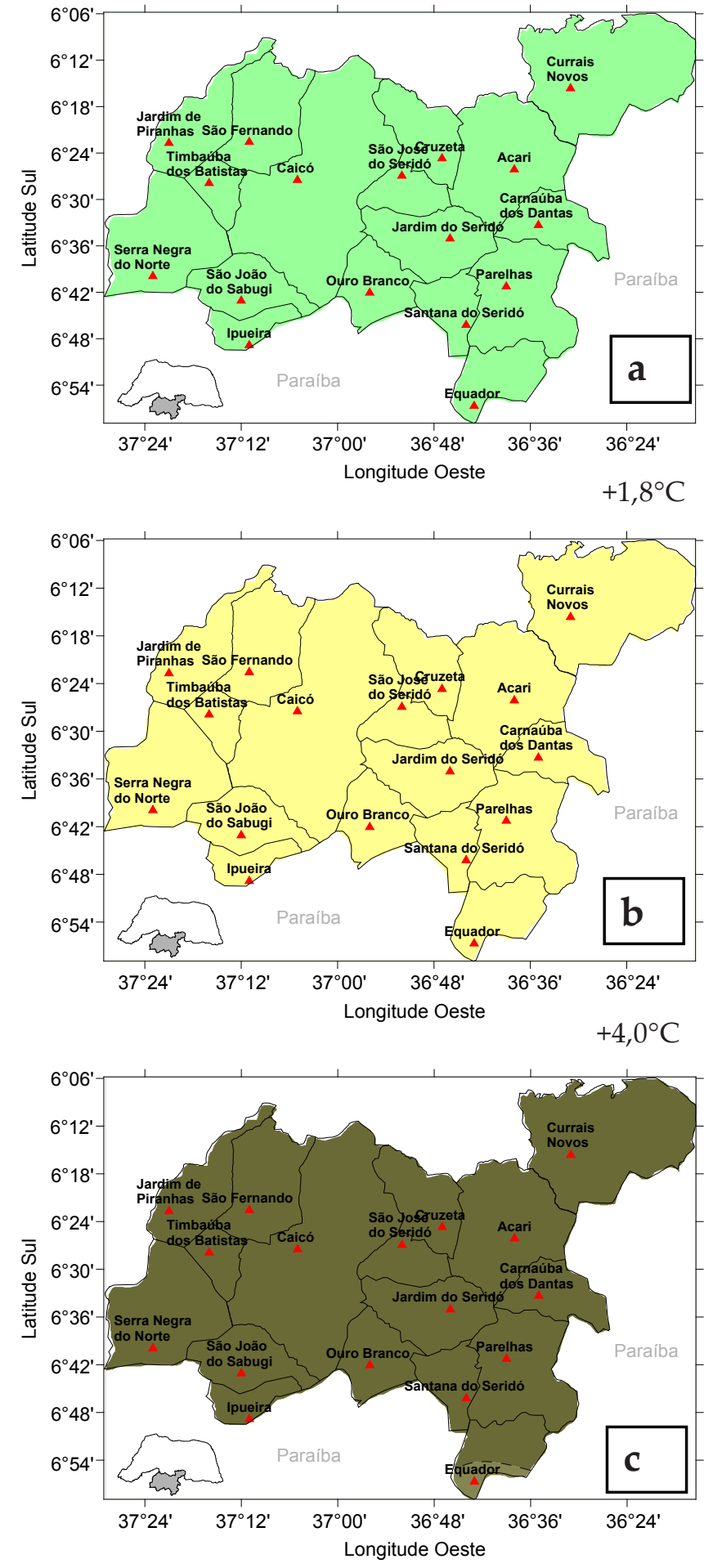

12334566789910111213141516 mm

Figura 7. Distribuição espacial de anomalia da EtoHS para o mês de março segundo os cenários $\left(\right.$ à $\left.0,5^{\circ} \mathrm{C}\right)$ (a), B1 (à $\left.1,8^{\circ} \mathrm{C}\right)(\mathrm{b})$ e A1FI (à $\left.4,0^{\circ} \mathrm{C}\right)(\mathrm{c})$.

Para o mês de julho as anomalias seguintes mostram valores mínimos, entre 2 e $3 \mathrm{~mm}\left(a ̀\right.$ a $\left.05^{\circ} \mathrm{C}\right)$ (Figura 8a); para o cenário B1 a diferença gradual fica por entre $6 \mathrm{e}$ $7 \mathrm{~mm}$, em torno de $4 \%$ (Figura 8b). E para um cenário pessimista essa diferença tende a ficar entre 11 e $13 \mathrm{~mm}$ para esse mês (Figura 8c).
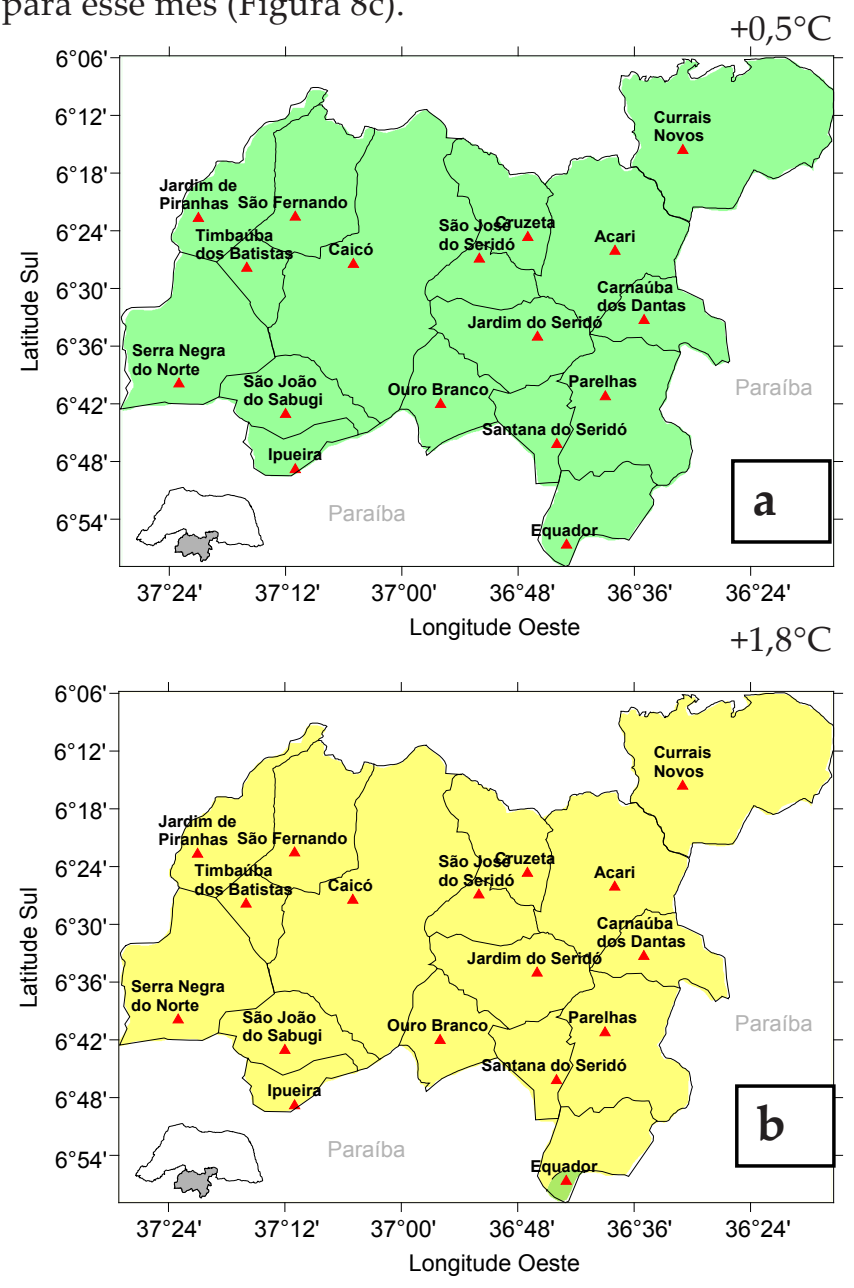

$+4,0^{\circ} \mathrm{C}$

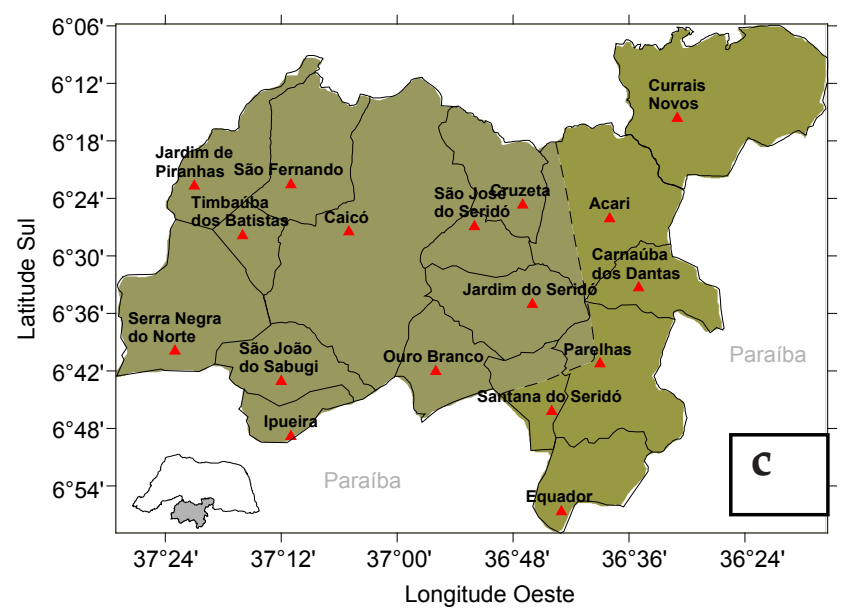

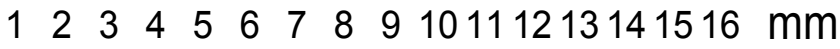

Figura 8. Distribuição espacial de anomalia da EtoHS para o mês de julho segundo os cenários $\left(a ̀\right.$ $\left.0,5^{\circ} \mathrm{C}\right)(\mathrm{a})$, B1 (à $\left.1,8^{\circ} \mathrm{C}\right)(\mathrm{b})$ e A1FI $\left.(a ̀), 0^{\circ} \mathrm{C}\right)(\mathrm{c})$. 
A Figura 9 mostra a distribuição espacial de anomalia para o mês de outubro em três cenários.
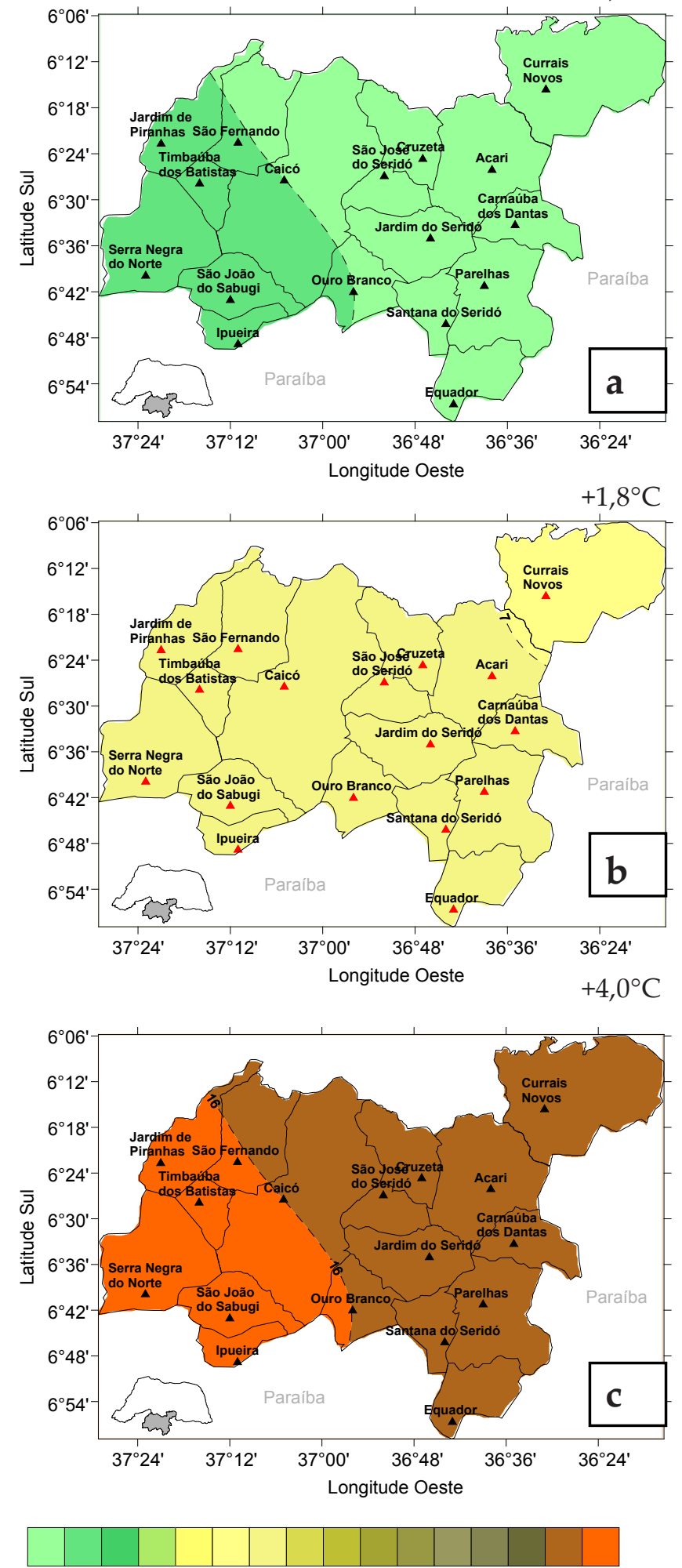

$12334566789910111213141516 \quad \mathrm{~mm}$

Figura 9. Distribuição espacial de anomalia da EtoHS para o mês de outubro segundo os cenários $\left(a ̀ 0^{\circ} \mathrm{C}\right)$ (a), B1 (à $\left.1,8^{\circ} \mathrm{C}\right)(\mathrm{b})$ e A1FI $\left(a ̀\right.$ 4, $\left.0^{\circ} \mathrm{C}\right)(\mathrm{c})$.
Viu-se que segundo a estimativa ao cenário de aumento na temperatura média de $0,5^{\circ} \mathrm{C}$ (Figura 9a) os valores distribuem-se de 2 a $4 \mathrm{~mm}$ na microrregião. Na melhor estimativa para um cenário (B1) (Figura 9b) varia em torno de $7 \mathrm{~mm}$ (região nordeste do Seridó) a $8 \mathrm{~mm}$ (no restante). E para o cenário $\left(a ̀\right.$ a $4,0^{\circ} \mathrm{C}$ ) (Figura $9 \mathrm{c}$ ) esses valores tendem a serem superiores a $15 \mathrm{~mm}$ ao mês, vistos sobre as localidades de Serra Negra do Norte, Timbaúba dos Batistas, Jardim de Piranhas e Ipueira.

O método de Hargreaves-Samani por apresentar resultados de evapotranspiração próximos aos médios mensais respondeu com valores satisfatórios, como se viu nas anomalias. Embora os cenários simulem alta na temperatura média do ar, esses valores apontam à mesma direção Oeste da microrregião conforme mostrou a distribuição da evapotranspiração anual (Figuras 3) e mensal (Figuras 6a, 6c e 6e).

\section{Considerações finais}

As simulações apresentadas pelo método de Hargreaves-Samani mostraram o quanto superestimaram (em torno de $5 \%$ ) os valores médios, considerando os cenários previstos. Esses resultados mostram que com relação aos cenários analisados, verifica-se a grande diferença no aumento da evapotranspiração anual e mensal. Valores esses que superam a própria classificação climática de Thornthwaite (1948), como sendo essencialmente megatérmico (com a ETP superior a $1.140 \mathrm{~mm} \cdot \mathrm{ano}^{-1}$ ) na qual descreve o clima do Nordeste Brasileiro. Dessa forma, acredita-se que com os cenários descritos, o aumento mínimo na temperatura do ar, implicaria bastante nas taxas de evapotranspiração sobre as localidades da microrregião do Seridó.

Os cenários segundo o IPCC que foram plotados conforme os aumentos na temperatura média do ar, utilizando dos métodos de evapotranspiração, mostraram que os valores resultantes apontam alta na metade oeste da região do Seridó. E em complemento a esses resultados aponta-se para questões com relação ao contínuo desenvolvimento da região, pois como foi visto os altos valores de Eto poderão acarretar sérios problemas às comunidades que necessitam da água disponível em açudes e reservatórios para o consumo humano, à agricultura familiar e a agropecuária.

Em vista disso entende-se que muitos estudos possam ser realizados para essa microrregião com a complementação da investigação micrometeorológica, assim como a instalação de equipamentos nas outras localidades para o monitoramento das condições ambientais, com o intuito de manterem informadas as autoridades representantes dos municípios para que possam tomar as medidas cabíveis para atender a toda a população da região. 


\section{Referências}

ALLEN, R. G.; PEREIRA, L. S.; RAES, D.; SMITH, M. Crop evapotranspiration - Guidelines for computing crop water requirements. Roma: FAO. (FAO Irrigation and Drainage Paper, 56). 300p. 1998.

AZEVEDO, B. M. Evapotranspiração de referência obtida com a razão de Bowen, lisímetro de pesagem e equação de Penman-Monteith utilizando sistemas automáticos. 1999. $81 \mathrm{f}$. Tese (Doutorado em Agronomia) - Escola Superior de Agricultura Luiz de Queiroz, Universidade de São Paulo, Piracicaba, 1999.

BACK, A. J. Desempenho de métodos empíricos baseados na temperatura do ar para a estimativa da evapotranspiração de referência em UrussangaSC. Revista Irriga, Botucatu, v.13, n.4, p.449-466, outubro-dezembro, 2008.

CAVALCANTI, E. P.; SILVA, V. P. R.; SOUSA, F. A. S. Programa computacional para a estimativa da temperatura do ar para a Região Nordeste do Brasil. Revista Brasileira de Engenharia Agrícola e Ambiental. Campina Grande-PB, v.10, n.1, p.140147, 2006.

D'ANGIOLELLA, G. L. B.; VASCONCELLOS, V. L. D. Planilha eletrônica para estimativa da radiação solar - ERS V.1.3-2002. Boletim da Sociedade Brasileira de Meteorologia. V. 27, $\mathrm{n}^{\circ}$. 01. Março de 2003, 50p.

EMPARN. Empresa de Pesquisa Agropecuária do Rio Grande do Norte. Disponível em http://www. emparn.rn.gov.br/climatologia. acesso em agosto de 2010.

FANAYA JÚNIOR, E. D.; LOPES, A. S.; OLIVEIRA, G. Q.; JUNG, L. H. Métodos empíricos para estimativa da evapotranspiração de referência para Aquidauana-MS. Irriga, Botucatu, v. 17, n. 4, p. 418 - 434, outubro - dezembro, 2012.

HARGREAVES, G. H.; SAMANI, Z. Reference crop evapotranspiration from temperature. Journal of Applied Engineering in Agriculture, St Joseph, v.1, n.2, p.96-99, 1985.

IBGE. Instituto Brasileiro de Geografia e Estatística. Disponível em http://www.ibge.gov.br/. acesso em agosto de 2010.

INMET. Instituto Nacional de Meteorologia. Disponível em http://www.inmet.gov.br/. acesso em agosto de 2010.

ISAIAS, E. M. B. I.; ISAIA, T.; VERSLYPE, C.; GARIGLIO, M. A. Avaliação do estoque lenheiro do Estado do Rio Grande do Norte - $1^{\mathrm{a}}$ etapa: Estratificação e mapeamento da vegetação nativa lenhosa através de composições coloridas do TM Landsat. PNUD/FAO-IBAMA. Nota técnica. N. 4, 29p, 1992.

KOUSKY, V. E.; CHU, P.S. Flutuations in Annual Rainfall for Northeast Brazil. Journal of the Meteorological Society of Japan, V.56, p. 457-465, 1978.

MATTOS, A.; BEZERRA, H. N.; BEZERRA, J. M.; OLIVEIRA, H. A. OLIVEIRA, J. N. P. Avaliação do balanço hídrico climatológico em região semiárida do Rio Grande do Norte, Brasil para cenários diferentes de temperatura do ar. Associação Interamericana de Engenharia Sanitária e Ambiental. AIDIS. Honduras. Setembro de 2013. Anais de Congresso.

MOTA, F. S. Meteorologia Agrícola, São Paulo, NOBEL, 1977. 376 p.

PEREIRA, A. R., ANGELOCCI, L. R., SENTELHAS, P. C.: Agrometeorologia: fundamentos e aplicações práticas. Guaíba: Agropecuária, 478p. 2002.

RAO, V. B.; LIMA, M. C.; FRANCHITO, S. H. Seasonal and interannual variations of rainfall over Eastern Northeast Brazil. Journal of Climate, v.6, n.9, p.1754-1763, Sept. 1993.

SANTOS, D. N. D.; SILVA, V. DE P. R., SOUSA, F. A. S.; SILVA, R. A. Estudo de alguns cenários climáticos para o Nordeste do Brasil. Revista Brasileira de Engenharia Agrícola e Ambiental. v.14, n.5, p.492-500, 2010.

SANTOS, W. O.; BATISTA, B. D. O.; ASSIS, J. P.; RODRIGUES, W. M.; SOBRINHO, J. E. Métodos de estimativa da evapotranspiração de Referência (Eto) para a região de Mossoró-RN. Revista Verde (Mossoró-RN - Brasil) v.5, n.5, (Número Especial) p. 210 - 221. Dezembro de 2010. Disponível em http://www.gvaa.com.br/revista/index.php/RVADS

SILVA, V. DE P. R.; BELO FILHO, A. F.; DA SILVA, B. B.; CAMPOS, J. H. B. C. Desenvolvimento de um sistema de estimativa da evapotranspiração de referência. Revista Brasileira de Engenharia Agrícola e Ambiental, v.9, n.4, p.547-553, 2005.

SILVA, V. J.; CARVALHO, H. P.; DA SILVA, 
C. R.; CAMARGO, R.; TEODORO, R. E. F.

Desempenho de diferentes métodos de estimativa da evapotranspiração de referência diária em Uberlândia-MG. Bioscience Journal, Uberlândia, v. 27, n. 1, p. 95-101, Jan/Feb. 2011

SOLOMON, S.; QIN, D.; MANNING, M.; CHEN, Z.; MARQUIS, M.; AVERYT, K. B.; TIGNOR, M.; MILLER, H. L. eds., IPCC, 2007: Summary for Policymakers. In Climate Change 2007: The Physical Science Basis. Contribution of Working, Group I to the Fourth Assessment Report of the Intergovernmental Panel on Climate Change. Cambridge, UK and New York, NY, USA:

Cambridge University Press.

THORNTHWAITE, C. W. An approach toward a rational classification of climate. Geographical Review, 38: p. 55-94. 1948. 